\title{
DIVERSIDADE GENÉTICA DE Enterolobium contortisiliquum (Vell.) Morong. NO BAIXO RIO SÃO FRANCISCO, POR MEIO DE MARCADORES RAPD ${ }^{1}$
}

\author{
Georgea da Cruz Santana ${ }^{2}$, Renata Silva Mann ${ }^{3}$, Roberio Anastacio Ferreira ${ }^{3}$, Itamara Bomfim Gois ${ }^{2}$, \\ Andrea dos Santos Oliveira ${ }^{4}$, Alessandra de Jesus Boari ${ }^{5}$, Sheila Valeria Alvares Carvalho ${ }^{6}$
}

\begin{abstract}
RESUMO - Enterolobium contortisiliquum Vell. Morong (Leguminosae-Mimosoideae) é uma espécie muito utilizada em programas de recuperação de matas ciliares no Baixo Rio São Francisco, devido ao seu rápido crescimento inicial. Assim, o objetivo deste trabalho foi avaliar, por meio de marcadores moleculares RAPD, a diversidade genética de oito indivíduos de uma população remanescente dessa espécie, visando contribuir para a definição de estratégias de coleta de sementes. Os indivíduos estão situados em uma área de 100 ha de mata ciliar do Baixo Rio São Francisco. Para a extração do DNA, pelo método CTAB 2\%, foram utilizadas folhas tenras dos indivíduos. Testaram-se 20 oligonucleotídios de 10 bases de seqüência arbitrária, cujos produtos foram separados em gel de agarose $0,8 \%$, submetidos à eletroforese horizontal, corados com brometode-etídio e visualizados em luz ultravioleta. A similaridade genética entre os indivíduos foi calculada pelo Coeficiente de Similaridade de Jaccard e a construção do dendrograma, realizada utilizando-se o método UPGMA. O valor médio de diversidade genética entre as matrizes foi de $49 \%$, variando de 33 a $85 \%$. Os indivíduos 6 e 7 apresentaram relativa proximidade genética (67\%), não sendo indicado o plantio de suas mudas ou semeadura direta para recuperação de área ciliar em locais muito próximos. A partir dos resultados observados, podem-se desenvolver estratégias para a coleta de sementes e produção de mudas, auxiliando, assim, programas de restauração ambiental.
\end{abstract}

Palavras-chave: Recuperação de área degradada, marcadores de DNA, vegetação ciliar e caráter de raridade.

\section{GENETIC DIVERSITY OF Enterolobium contortisiliquum (Vell.) Morong. IN THE LOW SAN FRANCISCO RIVER BY RAPD MARKERS}

\begin{abstract}
Enterolobium contortisiliquum Vell. Morong (Leguminosae-Mimosoideae) is very much used in riparian forest restoration programs in the Low San Francisco River because of its fast initial growth. The objective of this work was to evaluate by RAPD molecular markers the genetic diversity of eight individuals of a remaining population of this species, in order to contribute for the definition of strategies for seed production. The individuals are situated in an area of 100ha in the riparian forest of the Low San Francisco River. DNA extraction was carried out with young and tender leaves using $2 \%$ CTAB. Twenty primers of ten arbitrary sequence bases were used. The products were separated in $0.8 \%$ agarose horizontal gel electrophoresis, stained with Ethidium Bromide and visualized with ultraviolet light. The genetic similarity among the individuals was calculated by Jaccard Similarity Coefficient and dendrograms were obtained using the UPGMA method. The mean value for genetic diversity among individuals was 49\%, varying from 33\% to $85 \%$. Individuals 6 and 7 showed a high genetic similarity (67\%). Therefore, their planting
\end{abstract}

\footnotetext{
${ }^{1}$ Recebido em 11.05.2007 e aceito para publicação em 19.05.2008.

${ }^{2}$ Graduação em Engenharia Florestal da Universidade Federal de Sergipe (UFS), São Cristovão-SE.

${ }^{3}$ Departamento de Engenharia Agronômica da UFS. E-mail: < rsmann@sergipenet.com.br> .

${ }^{4}$ Programa de Pós-Graduação em Fitotecnia da Universidade Federal de Lavras (UFLA), Lavras-MG.

${ }^{5}$ Embrapa Amazônia Oriental, Trav. Dr. Enéas Pinheiro s/n, Marco, 66095-100 Belem, PA.

${ }^{5}$ Programa de Pós-Graduação da UFS.
} 
or direct seeding to restore riparian areas is not indicated in places near to each other. The results showed that strategies for seed collection and seedling production can be developed to assist in restoration programs.

Keywords: Degraded area restoration, DNA markers, riparian vegetation and rarity character.

\section{INTRODUÇÃO}

Os ecossistemas naturais representam uma fonte imensurável de recursos genéticos atuais e potenciais ao homem, tanto como fonte direta de produtos quando gerando outros serviços. Grande parte desses recursos vem sendo destruída de modo irreversível, causando alterações profundas nesses ecossistemas e conseqüências, às vezes, desastrosas ao meio ambiente (KAGEYAMA, 1987).

Dentre as formações florestais mais impactadas pelas atividades humanas, encontram-se as matas ciliares, as principais responsáveis pela estabilidade marginal dos cursos de água, manutenção do regime hídrico e qualidade de suas águas. Além disso, essas áreas têm sido consideradas corredores ecológicos extremamente importantes, pois favorecem o fluxo gênico ao longo do rio, devido à intensa circulação de animais e dispersão vegetal nesses locais. Assim, torna-se fundamental o desenvolvimento imediato de estudos genéticos populacionais das espécies que compõem tais áreas, para fins de conservação genética in situ ou utilização como "áreas para coleta de sementes" (SEBBENN et al., 2003).

Informações sobre ecologia e genética, em populações naturais, são incipientes na literatura em função da alta diversidade e complexidade de espécies, trazendo dificuldades na amostragem e nas metodologias apropriadas para o seu estudo. Esse conhecimento é essencial para o entendimento da estrutura genética dessas populações e, portanto, para o delineamento de estratégia de conservação, melhoramento e manejo sustentável com atividades para a definição do tamanho de reservas, manejo adequado das espécies, recuperação de áreas degradadas e coleta de sementes para plantios com espécies nativas (KAGEYAMA et al., 2003).

A análise da variabilidade genética em populações, por meio de marcadores moleculares RAPD (Random Amplified Polymorphic DNA), vem sendo muito utilizada devido às facilidades encontradas na utilização dessa técnica. Além disso, esses marcadores tendem

R. Árvore, Viçosa-MG, v.32, n.3, p.427-433, 2008 a fornecer marcas relativamente específicas de populações, raças ou espécies (ZUCCHI, 2002), garantindo uma boa amostragem do geno ma do indivíduo, tanto para as regiões codificadas quando para as regiões repetidas (PIGATO e LOPES, 2001). Em seu trabalho com RAPD, Zimback et al. (2004) estudaram a diversidade genética em três populações de Trichilia pallida Swartz (Meliaceae), obtendo valores de diversidade entre e dentro das populações, que indicaram a necessidade do estabelecimento de estratégias de conservação nas áreas do estudo. Pigato e Lopes (2001), monitorando a variabilidade genética de uma população de Eucalyptus urophilla S. T. Blake, submetida a um teste de progênies, concluiu que o marcador RAPD mostrou-se também eficiente neste tipo de estudo.

A espécie em questão, Enterolobium contortisiliquum (Vell.) Morong., LeguminosaeMimosoideae, vulgarmente conhecida como tamboril, é decídua, heliófita, seletiva higrófita, dispersa em várias formações florestais. Pode ser utilizada na arborização urbana e na recuperação de áreas degradadas (LORENZI, 1998). Quanto à sua classificação no estádio sucessional, é considerada, de acordo com Oliveira Filho et al. (1995), uma espécie pertencente ao grupo ecológico clímax exigente de luz. É encontrada, freqüentemente, colonizando áreas desmatadas, em clareiras e borda de mata.

Este trabalho, portanto, teve por objetivos avaliar, por meio de marcadores moleculares RAPD, a diversidade genética de indivíduos de Enterolobium contortisiliquum localizados em área de mata ciliar na região do Baixo Rio São Francisco e, assim, definir estratégias para a coleta de sementes e produção de mudas para serem utilizadas em programas de recuperação de matas ciliares na região.

\section{MATERIAL E MÉTODOS}

\subsection{Coleta do material vegetal}

Coletou-se material vegetal de oito indivíduos de Enterolobium contortisiliquum, os únicos encontrados 
em uma área de 100 ha $(10 \mathrm{~km} / 100 \mathrm{~m}$ de largura $)$ de mata ciliar no Baixo Rio São Francisco sergipano (Figura 1), entre os Municípios de Neópolis (10¹8'39" S e 36 34'56" W) e Santana do São Francisco $\left(10^{\circ} 15^{\prime} 55^{\prime \prime}\right.$ S e $36^{\circ} 38^{\prime} 15^{\prime \prime}$ W). Por apresentar pequena população nessa área, a espécie está sendo considerada em caráter de raridade, de acordo com Townsend et al. (2006).

O material vegetal coletado constituiu-se de folhas tenras, que foram identificadas e mantidas no gelo seco para o transporte até o laboratório, e, em seguida, procedeu-se às extrações do DNA.

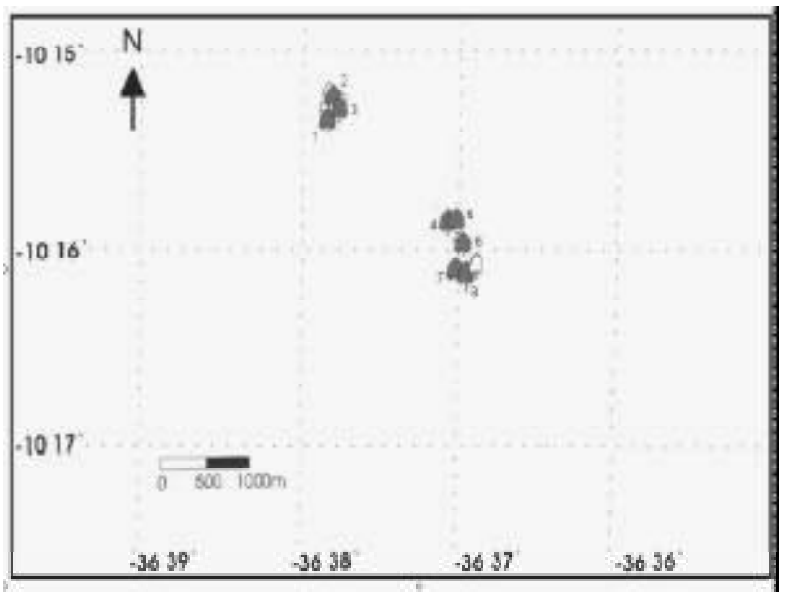

Figura 1 - Mapa ilustrando a localização dos indivíduos de Enterolobium contortisiliquum na área de mata ciliar na região do Baixo Rio São Francisco. UFS, São Cristóvão, SE, 2006.

Figure 1-Map illustrating the location of the individuals of Enterolobium contortisiliquum in the riparian area in the Low San Francisco River. UFS, São Cristóvão-SE, 2006

\subsection{Extração do DNA}

A extração do DNA foi baseada no método descrito por Silva-Mann et al. (1999) modificado. Utilizaram-se $2 \mathrm{~g}$ de folhas tenras maceradas com nitrogênio líquido. Após a maceração, essas folhas foram transferidas para microtubos contendo tampão CTAB 2\% (Cetil Trimetil Brometo de Amônio) e $20 \mu \mathrm{L}$ de $\beta$-mercaptoetanol para retardar a oxidação de metabólitos secundários. Esse material foi incubado por $30 \mathrm{~min}$ em banho-maria a $65^{\circ} \mathrm{C}$. Em seguida, as amostras passaram por um processo de purificação - quando foi-lhes adicionado clorofórmio: álcool isoamílico (24:1) - homogeneizadas, por meio de lentas inversões, e centrifugadas a $5.000 \mathrm{rpm}$, por $5 \mathrm{~min}$, sendo o sobrenadante (fase aquosa) coletado. Essa etapa foi repetida para uma melhor purificação do DNA.

O sobrenadante obtido foi pipetado e transferido para um tubo contendo $1.000 \mathrm{~L}$ de álcool acetato de amônia. As amostras foram mantidas em freezer por $24 \mathrm{~h}$ para a precipitação do DNA. O precipitado foi coletado e removido para um microtubo contendo álcool 70\%, e centrifugado por $5 \mathrm{~min}$ a $14.000 \mathrm{rpm}$. Em seguida, a fase líquida foi descartada e o precipitado, posto para secar em temperatura ambiente. Depois de seco, este foi dissolvido em $300 \mu \mathrm{L}$ de TE (Tris-HCl 10 mM, pH 8,0; EDTA 1 Mm). As amostras foram armazenadas em "freezer" a $21^{\circ} \mathrm{C}$.

A avaliação da qualidade do DNA foi realizada em gel de agarose $0,8 \%$, em Tris - Borato - EDTA $(0,8$ $\mathrm{g}$ de agarose; $100 \mathrm{~mL}$ de Tris - Borato - EDTA (TBE) $0,5 \mathrm{X})$, submetido à eletroforese a $80 \mathrm{~V}$.

\subsection{Análise RAPD}

Depois da extração do DNA, deu-se início às reações de RAPD. As amplificações foram baseadas no método descrito por Williams et al. (1990), com modificações. O coquetel de reagentes de cada matriz foi composto por 2,92 $\mu \mathrm{L}$ de água ultrapura; 1,30 $\mu \mathrm{L}$ de tampão PCR $10 \mathrm{X} ; 1 \mu \mathrm{L}$ de cloreto de magnésio $25 \mathrm{mM}$; 1,04 $\mu \mathrm{L}$ de dNTPs; 1,04 L de BSA (Soro Albumina Bovina); 0,2 $\mu \mathrm{L}$ da enzima Taq Polimerase; 2,5 $\mu \mathrm{L}$ do oligonucleotídio decâmero; e $3 \mu \mathrm{L}$ do DNA. Foram testados 20 oligonucleotídios de 10 bases de seqüência arbitrária da marca IDT ("Integrated DNA Technologies") (Tabela 1).

O programa de amplificação do DNA consistiu de uma temperatura inicial de $94{ }^{\circ} \mathrm{C}$ por $5 \mathrm{~min}$, seguida de 45 ciclos, que envolveram temperaturas de $94{ }^{\circ} \mathrm{C}$ por $1 \mathrm{~min}, 36^{\circ} \mathrm{C}$ por $2 \mathrm{~min}$. e $72{ }^{\circ} \mathrm{C}$ por $1 \mathrm{~min}$. Essa amplificação se deu em termociclador Uniscience Biometra Tpersonal.

Os produtos da amplificação foram separados por eletroforese, em cuba horizontal, contendo tampão TBE $0,5 \mathrm{X}$, por um período de $1 \mathrm{~h}$ em gel de agarose $0,8 \%$. Em seguida, o gel foi corado em uma solução de brometo de etídio $(0,5 \mu \mathrm{g} / \mathrm{mL})$ por 10 a $15 \mathrm{~min}$ e os produtos da amplificação foram visualizados e fotografados sob luz ultravioleta.

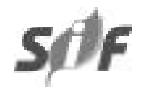

R. Árvore, Viçosa-MG, v.32, n.3, p.427-433, 2008 
Tabela 1 - Oligonucleotídios utilizados e respectiva seqüência de bases, número total de bandas observadas, número de bandas polimórficas e porcentagem de polimorfismo de oito indivíduos de Enterolobium contortisiliquum, em populações naturais no Baixo Rio São Francisco. UFS, São Cristóvão, SE, 2006

Table 1 - Primers used and respective base sequences, total band numbers, number of polymorphic bands and percentage polymorphism for eight individuals of Enterolobium contortisiliquum, in natural populations in the Low San Francisco River. UFS, São Cristóvão-SE, 2006

\begin{tabular}{ccccc}
\hline oligonucleotídios & $\begin{array}{c}\text { Seqüência } \\
\text { 5'-3' }\end{array}$ & Número total de bandas & $\begin{array}{c}\text { Número de bandas } \\
\text { polimórficas }\end{array}$ & \% de polimorfismo \\
\hline 01 & CAG GCC CTT C & 3 & 0 & 0,0 \\
02 & TGC CGA GCT G & 5 & 2 & 40,0 \\
03 & GTT TCG CTC C & 0 & 0 & 0,0 \\
04 & TGA TCC CTG G & 3 & 2 & 66,7 \\
05 & TTC GAG CCA G & 5 & 2 & 40,0 \\
06 & GTG AGG CGT C & 2 & 1 & 50,0 \\
07 & ACC GCG AAG G & 4 & 3 & 75,0 \\
08 & GGA CCC AAC C & 7 & 4 & 57,0 \\
09 & CCC AAG GTC C & 4 & 0 & 0,0 \\
10 & GGT GCG GGA A & 4 & 3 & 75,0 \\
11 & ACG GAT CCT G & 4 & 1 & 25,0 \\
12 & GAG GAT CCC T & 4 & 3 & 75,0 \\
13 & CTA CGG AGG A & 3 & 2 & 66,7 \\
14 & GGC ACT GAG G & 3 & 2 & 66,7 \\
15 & GGT CGG AGA A & 6 & 5 & 83,3 \\
16 & TCG GAC GTG A & 1 & 0 & 0,0 \\
17 & ACC TGG ACA C & 2 & 0 & 0,0 \\
18 & GGA GGA GAG G & 3 & 2 & 66,7 \\
19 & CCC GGC ATA A & 5 & 3 & 60,0 \\
20 & AAA GTT GGG A & 3 & 2 & 66,7 \\
\hline Total & & 71 & 37 & \\
\hline
\end{tabular}

\subsection{Análise estatística dos dados moleculares}

A partir da leitura das bandas no gel foi construída uma matriz binária, em que (0) indicava ausência e (1), a presença de bandas.

A similaridade genética entre as matrizes de $E$. contortisiliquum foi calculada pelo coeficiente de similaridade de Jaccard empregando-se o programa NTSYS pc 2.1 (ROHLF, 2001). As similaridades obtidas (Sji) foram calculadas, empregando-se a seguinte expressão:

$$
S j i=\frac{a}{a+b+c}
$$

em que, a representa a presença de bandas em ambos os genótipos, $\mathrm{b}$ a presença de banda no primeiro genótipo e ausência no segundo e a presença no segundo e ausência no primeiro.

A construção do dendrograma foi realizada, utilizando-se o coeficiente de similaridade de Jaccard, o método de agrupamento de médias aritméticas não ponderadas - UPGMA (ROHLF, 2001) e o programa NTSYS pc 2.1 (ROHLF, 2001).

\section{RESULTADOS E DISCUSSÃO}

No mapa de localização dos indivíduos de $E$. contortisiliquum (Figura 1), observou-se que estes se apresentam concentrados em dois grupos, distantes $2,125 \mathrm{~km}$ entre si. O número reduzido de indivíduos dessa espécie em uma extensão de mata ciliar de 100 ha, juntamente com a proximidade entre alguns dos indivíduos remanescentes, consolida a necessidade de estudos genéticos urgentes, a fim de avaliar a diversidade genética destes e definir estratégias para a manutenção da sustentabilidade na área. Deve-se considerar que, quanto maior for o grau de parentesco dentro de pequenos agrupamentos de indivíduos de determinada população, maior poderá ser a endogamia nas progênies (MORAES et al., 2005). 


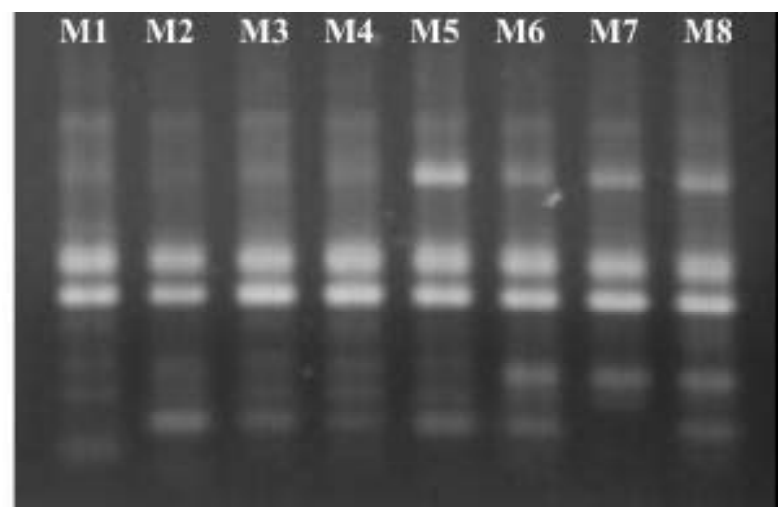

Figura 1 - Produtos de amplificação de RAPD gerados com o oligonucleotídio no 19 em indivíduos deEnterolobium contortisiliquum de ocorrência no Baixo Rio São Francisco. UFS, São Cristóvão, SE, 2006.

Figure 1-Products of RAPD amplification generated with the primer 19 in individuals of Enterolobium contortisiliquum of occurrence in Low San Francisco River. UFS, São Cristóvão, SE, 2006.

$\mathrm{Na}$ análise de RAPD, dos 20 oligonucleotídios utilizados, 19 geraram 71 produtos de amplificação (Figura 2), sendo que, desse total, 37 bandas foram polimórficas, com a porcentagem de polimorfismo variando de $0 \%$ a $83,3 \%$, com média de $45,7 \%$ (Tabela 1 ).

O número de bandas amplificadas variou de acordo com o oligonucleotídio. Observou-se que, exceto o oligonucleotídio 3, que não amplificou nenhuma banda, o menor número de bandas (1) foi encontrado pela amplificação usando-se o oligonucleotídio 16, enquanto no no 8 se observou o maior número de bandas (7). No entanto, considerando-se o polimorfismo, o no 15 foi o que produziu maior número de bandas polimórficas (5).

O valor médio de similaridade genética observado na análise de matrizes deE. contortisiliquum foi $37,68 \%$, e os valores variaram de $15 \%$ a $67 \%$ (Tabela 2 ).

Confrontando os dados obtidos da avaliação da diversidade genética com a localização dos indivíduos na área de estudo, observou-se baixa similaridade genética entre as matrizes 7 e 8 , cerca de $46 \%$, apesar de elas estarem localizadas a aproximadamente $40 \mathrm{~m}$ de distância, quando o espaço mínimo recomendado entre árvores-matriz é de 50 a 100 m (KAGEYAMA e GANDARA, 1999). Da mesma forma, quando se observa a distância entre as matrizes 6 e 7, de mais de $110 \mathrm{~m}$, e a confronta com o valor de similaridade de $67 \%$ entre estas matrizes, nota-se uma similaridade relativamente alta, apesar de distância entre elas ser superior à recomendada.

A partir desses resultados, verifica-se que, a depender das características da espécie (fenologia, mecanismos de dispersão vegetal etc), a recomendação da distância mínima entre matrizes não precisa ser rigorosamente seguida. Assim, também é importante ter-se em mente que, mesmo utilizando essa estratégia, as sementes coletadas podem reter algum grau de endogamia biparental se os cruzamentos ocorrerem dentro das vizinhanças das árvores maternas (GUSSON et al., 2005).

Os valores de similaridade permitiram a divisão desses indivíduos em dois grandes grupos, utilizando como critério de corte a $40 \%$, semelhantes entre si em $28 \%$ (Figura 3 ). O primeiro grupo foi composto pelos indivíduos 1, 2, 3, 4 e 5 e o segundo, pelos indivíduos 6, 7 e 8. De forma geral, houve uma congruência dos dois agrupamentos obtidos com o dendrograma e os dois grupos resultantes da interpretação do mapa de localização, diferindo apenas pelos indivíduos 4 e 5, que apresentaram maior proximidade genética com os indivíduos 1, 2 e 3, apesar de se encontrarem espacialmente mais próximos dos indivíduos 6,7 e 8.

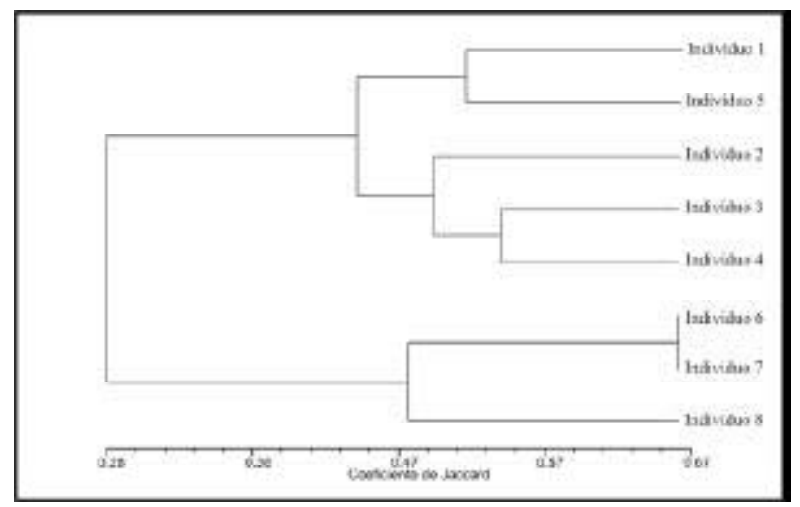

Figura 3 - Dendrograma construído por meio do método de agrupamento de médias aritméticas não ponderadas (UPGMA), a partir dos valores de similaridade genética entre os indivíduos Enterolobium contortisiliquum na região do Baixo Rio São Francisco. UFS, São Cristóvão, SE, 2006.

Figure 3 - Dendrogram built by the clustering unweighted pair group method with arithmetic mean (UPGMA), with the genetic similarity values among the individuals of Enterolobium contortisiliquum in the region of the Low San Francisco River. UFS, São Cristóvão, SE, 2006.

R. Árvore, Viçosa-MG, v.32, n.3, p.427-433, 2008 
Tabela 2 - Similaridades genéticas (\%), baseadas no coeficiente de Jaccard, entre indivíduos de Enterolobium contortisiliquum situados em populações naturais na região do Baixo Rio São Francisco. UFS, São Cristóvão, SE, 2006

Table 2 - Genetic similarities (\%), based on the Jaccard Coefficient, among individuals of Enterolobium contortisiliquum located in natural populations in the Low San Francisco River. UFS, São Cristóvão-SE, 2006

\begin{tabular}{|c|c|c|c|c|c|c|c|c|}
\hline Indivíduos & 1 & 2 & 3 & 4 & 5 & 6 & 7 & 8 \\
\hline 1 & 100 & & & & & & & \\
\hline 2 & 50 & 100 & & & & & & \\
\hline 3 & 50 & 52 & 100 & & & & & \\
\hline 4 & 40 & 47 & 54 & 100 & & & & \\
\hline 5 & 52 & 36 & 53 & 38 & 100 & & & \\
\hline 6 & 31 & 19 & 43 & 27 & 34 & 100 & & \\
\hline 7 & 27 & 15 & 39 & 28 & 27 & 67 & 100 & \\
\hline 8 & 24 & 21 & 30 & 24 & 31 & 50 & 46 & 100 \\
\hline
\end{tabular}

Esses resultados permitem inferir sobre a diversidade genética entre e dentro de grupos de indivíduos. Possivelmente, no estabelecimento dessas populações, pólen ou sementes foram dispersas a uma distância que permitisse abranger áreas dos grupos 1 e 2 , fato esse comprovado pela relativa proximidade genética dos indivíduos 4 e 5 (grupo 2) com os 1, 2 e 3 (grupo 1), o que se pode traduzir em fluxo gênico. No entanto, diversos autores assinalaram o fato de que nem sempre as distâncias de dispersão de pólen ou sementes refletem diretamente o fluxo gênico efetivo, sendo necessária a utilização de marcadores genéticos para efetivamente se estimarem intercruzamentos e movimentos de genes por meio de sementes (MARTINS, 1987).

A estrutura genética espacial, à semelhança da estudada neste trabalho com E. cortortisiliquum, é importante tanto para a conservação e manejo quanto para fins de melhoramento, possibilitando a formação de amostras mais significativas com certa diversidade em populações naturais de plantas, colaborando, assim, com a sustentabilidade dos recursos genéticos (LACERDA e KAGEYAMA, 2003).

\section{CONCLUSÕES}

- Por meio da análise de agrupamento usando como critério de corte a $40 \%$ de similaridade, constatouse a formação de dois grupos distintos.

- Os indivíduos 6 e 7 apresentam relativa proximidade genética (67\%), não sendo indicado o plantio de suas sementes ou mudas em áreas muito próximas.

- A coleta de sementes para produção de mudas em projetos de restauração, nessa região, pode incluir todos os indivíduos, priorizando os de maior diversidade, ou seja, os pares 6 e $2 ; 6$ e $4 ; 7$ e 2 ; 7 e $1 ; 8$ e $2 ; 8$ e $4 ; 8$ e $5 ;$ e 7 e 4 .

\section{REFERÊNCIAS}

CAVALLARI NETO, M. Efeito do manejo na diversidade genética de populações naturais de Tabebuia cassinoides Lam (DC), por marcadores isoenzimáticos . 2004. 67f. Dissertação (Mestrado em???) Escola Superior de Agricultura “Luiz de Queiroz", Piracicaba, 2004.

GUSSON, E.; SEBBENN, A. M.; KAGEYAMA,P. Y. Diversidade e estrutura genética espacial em duas populações de Eschweilera ovata. Scientia Forestalis, n.67, p.123-135, abril. 2005.

KAGEYAMA, P. Y. Conservação “in situ” de recursos genéticos de plantas. IPEF. n.35, p.7-37, 1987.

KAGEYAMA, P. Y.; GANDARA, F. B. Restauração, conservação genética e produção de sementes. ln: SIMPÓSIO MATA CILIAR: CIÊNCIA E TECNOLOGIA, 1999, Belo Horizonte. Anais... Lavras: Universidade Federal de Lavras, 1999. p.59-68.

KAGEYAMA, P. Y. et al. Diversidade genética em espécies arbóreas tropicais de diferentes estágios sucessionais por marcadores genéticos. Scientia Forestalis, n.64, p.93-107, dezembro, 2003.

LACERDA, C. M. B.; KAGEYAMA, P. Y. Estrutura genética espacial de duas populações naturais de Myracrodruon urundeuva $\mathrm{M}$. Allemão na região semi-árida, Brasil. Revista Árvore, v.27, n.2, p.145-150, 2003. 
LORENZI, H. Árvores brasileiras: manual de identificação e cultivo de plantas arbóreas nativas e cultivo de plantas arbóreas nativas do Brasil. 2.ed. Nova Odessa: Plantarum, 1998. v.1.352p.

LUCA, A. Q. Fenologia, potencial germinativo e taxa de cruzamento de uma população de paineira (Chorisia speciosa St. Hil. Bombacaceae) em área ciliar implantada. 2002. 87f. Dissertação (Mestrado em???) - Escola Superior de Agricultura “Luiz de Queiroz”, Piracicaba, 2002.

MARTINS, P. S. Estrutura populacional, fluxo gênico e conservação "in situ”. IPEF, n.35, p.71-78, 1987.

MORAES, M. L. T.; KAGEYAMA, P. Y.; SEBBENN, A. M. Diversidade e estrutura genética em duas populações de Myracrodruon urundeuva Fr. All. sob diferentes condições antrópicas.

Revista Árvore, v.29, n.2, p.281-289, 2005.

OLIVEIRA-FILHO, A. T. et al. Estudos florísticos e fitossociológicos em remanescentes de matas ciliares do Alto e Médio Rio Grande. Belo Horizonte: CEMIG/UFLA/FAEPE, 1995. 27p.

PIGATO, S. M. P. C.; LOPES, C. R. Caracterização silvicultural, botânica e avaliação da variabilidade genética por meio de marcadores moleculares RAPD em um teste de Progênies de Eucalyptus urophylla S. T. Blake. Scientia Forestalis, n.60, p.135-148, 2001.

ROHLF, F. J. Numerical taxonomy and multivariate analysis system. New York: 2001.
SEBBENN, A. M.; KAGEYAMA, P. Y.; VENCOVSKY, R. Conservação genética in situ e número de matrizes para a coleta de sementes em população de Genipa americana L. Scientia Forestalis, n.63, p.13-22, 2003.

SILVA-MANN, R.; DAVIDE, L. C.; SANTOS, J. B. Diversidade genética em coníferas: uma aproximação utilizando-se acículas. Ciências e Agrotecnologia, v.23, n.1, p.214-221, 1999.

TOWNSEND, C. R; BEGON, M.; HARPER, J. L. Fundamentos em ecologia. 2.ed. Porto Alegre: Artmed, 2006. 592p.

VASCONCELOS, G. M. P. Diversidade genética de Myrciaria floribunda (West ex Willdenow) Berg (Cambuí) em paisagem fragmentada da Serra da Mantiqueira, MG. 2002. 72f. Dissertação (Mestrado em???) - Escola Superior de Agricultura “Luiz de Queiroz”, Piracicaba, 2002.

WILLIAMS, J. G. K. et al. DNA polymorphisms amplified as arbitrary are useful genetics markers. Nucleic Acids Resources, v.18, p.6531-6536, 1990.

ZIMBACK, L. et al. Estrutura genética de populações de Trichilia pallida Swartz (Meliaceae) por marcadores RAPD. Scientia Forestalis, n.65, p.114-119, 2004.

ZUCCHI, M. I. Análise da estrutura gênica de Eugenia dysenterica DC utilizando marcadores RAPD e SSR . 2002. 130f. Tese (Doutorado em???) - Escola Superior de Agricultura "Luiz de Queiroz", Piracicaba, 2002. 